\title{
Effects of long-term multidisciplinary inpatient therapy on body composition of severely obese adolescents
}

\author{
Wagner Luiz do Prado, ${ }^{1}$ Alena Siegfried, ${ }^{2}$ Ana R. Dâmaso, ${ }^{3}$ \\ June Carnier, ${ }^{1}$ Aline de Piano, ${ }^{1}$ Wolfgang Siegfried ${ }^{2}$
}

\begin{abstract}
Objective: To describe the effects of long-term multidisciplinary inpatient therapy on body composition of severely obese adolescents.

Methods: A total of 728 extremely obese adolescents, including 249 boys (aged $15.25 \pm 1.56$ years) and 479 girls (aged 15.34 \pm 1.59 years) received multidisciplinary therapy during a period of 3 to 9 months. The therapy consisted of reduced energy intake, dietetic education, physical exercises and psychological therapy. Body composition was assessed by bioelectrical impedance analysis, and physical capacity was assessed by the multistage cycle ergometer test. Type and duration of each activity were recorded using a daily controlled activity diary.

Results: There was a significant decrease $(p<0.05)$ in body mass $(27.84 \pm 12.49 \mathrm{~kg}$ for boys and $21.60 \pm 9.87 \mathrm{~kg}$ for girls), body mass index $\left(9.19 \pm 3.88 \mathrm{~kg} / \mathrm{m}^{2}\right.$ for boys and $7.72 \pm 3.98 \mathrm{~kg} / \mathrm{m}^{2}$ for girls) and fat mass. In addition, the percentage of fat free mass increased significantly $(p<0.05)$ in boys (from $58.8 \pm 6.41$ to $69.98 \pm 7.43 \%$ ) and in girls (from $51.86 \pm 4.96$ to $60.04 \pm 5.65 \%$ ).
\end{abstract}

Conclusion: Long-term multidisciplinary approach allows significant reduction in severe obesity, preserving growth and percentage of fat free mass.

J Pediatr (Rio J). 2009;85(3):243-248: Adolescent, body composition, body weight loss, exercise, nutrition, obesity.

\section{Introduction}

Childhood obesity has reached epidemic proportions worldwide despite major efforts to promote weight reduction. The prevalence has increased at an alarming rate, affecting more than $75 \%$ of overweight and obese children living in low- and middle-income countries, particularly in urban settings. ${ }^{1}$ In Brazil, 6 million children and adolescents are overweight and obese. ${ }^{2}$ Childhood obesity results in many comorbidities that make up the metabolic syndrome. ${ }^{3,4}$ Low self-esteem has been reported to influence depression, social interactions and ability to lose weight. ${ }^{5}$
Treatment of obese adolescents should aim at decreasing fat mass (FM), avoiding loss of lean body mass, ensuring adequate growth and development, and preventing cyclic weight regain. ${ }^{6-8}$ Improving well-being is a second major aspect since psychological disturbances and social distress tend to be early features of obesity in the young. As such a multidisciplinary therapy proves to be difficult to reach in the usual environment. Inpatient units have been designed to help adolescents suffering from the most severe forms of obesity. ${ }^{9}$ However, body weight (BW) loss is usually

1. Programa de Pós-Graduação em Nutrição, Universidade Federal de São Paulo - Escola Paulista de Medicina (UNIFESP-EPM), São Paulo, SP, Brazil.

2. Obesity Rehabilitation Centre INSULA, Berchtesgaden, Germany.

3. Programa de Pós-Graduação em Nutrição, UNIFESP-EPM, São Paulo, SP, Brazil. Departamento de Biociências, UNIFESP, Santos, SP, Brazil.

No conflicts of interest declared concerning the publication of this article.

Suggested citation: do Prado WL, Siegfried A, Dâmaso AR, Carnier J, de Piano A, Siegfried W. Effects of long-term multidisciplinary inpatient therapy on body composition of severely obese adolescents. J Pediatr (Rio J). 2009;85(3):243-248.

Manuscript received Nov 13 2008, accepted for publication Mar 042009.

doi:10.2223/JPED.1889 
associated with significant declines in FM and fat free mass (FFM).

In children, it has been shown that hypocaloric diets alone induce FM and FFM reductions, which could explain the decreases in the basal metabolic rate (BMR) and thermic effect of food during the weight reduction program. ${ }^{10}$ In contrast, a weight reduction program including hypocaloric diet, exercise, behavior modification, significant decreases in BW and FM without significant reductions in FFM and BMR has been reported. ${ }^{11}$ Preservation of FFM is desirable for maintenance of energy expenditure (EE). And other important aspects are prevention of BW regain, improvement of physical capacities of post-obese children and adolescents, as well as possibility of performing normal physical activities and interacting with peers. ${ }^{12}$

Changes in body composition differ markedly between boys and girls during puberty. Hormonal changes that influence patterns in body fat accumulation and lean body mass leading to opposite trends, in boys and girls, have been well described in non-obese adolescents. ${ }^{13}$ Moreover, current data on the long-term effects of weight management programs for childhood obesity are limited. ${ }^{14}$

As part of first-line medical intervention, most patients will be offered exercise and/or dietary intervention program. In such a lifestyle intervention program, two main goals are set: (i) weight loss; and (ii) enhanced physical workload capacity. However, further studies are needed to define the optimal intervention program for obese patients. ${ }^{15}$

Therefore, the aim of this study was to describe the effects of a multidisciplinary weight loss intervention based on moderate dietary restriction, regular physical training, nutritional, psychological and educational support on body composition of male and female adolescents suffering from severe obesity.

\section{Methods}

A total of 728 extremely obese adolescents, including 249 boys (age $15.25 \pm 1.56$ years) and 479 girls (age $15.34 \pm 1.59$ years), were admitted at the Rehabilitation Centre Insula, Germany, for a planned period of 3 to 9 months of multidisciplinary inpatient obesity treatment after clinical diagnostic from several health institutions and approved health insurance from Germany.

This study was carried out in accordance with the principles of the Declaration of Helsinki II and was formally approved by the Institutional Ethical Committee. Informed consent was obtained from all subjects and/or their parents, and agreement of the adolescents and their families to participate was on a voluntary basis.

The mean duration of stay was 5.88 months. Mean body mass index (BMI) at admission was $41.25 \pm 7.06 \mathrm{~kg} / \mathrm{m}^{2}$ for boys and $40.01 \pm 6.46 \mathrm{~kg} / \mathrm{m}^{2}$ for girls, respectively. Inclusion criteria were BMI above the 99.5 percentile of the Centers for Disease Control and Prevention (CDC $)^{16}$ and associated metabolic disorders (such as hyperinsulinemia, or diabetes mellitus type 2, hyperlipidemia, and hyperuricemia), orthopedic problems, psychological disturbances following extreme obesity, and motivation for long-term therapy. Exclusion criteria were untreated psychiatric disorders, lack of motivation and obesity syndromes requiring permanent control.

The characteristics of the population are shown in Table 1. Patients were housed in therapeutic units of approximately 16 patients, except during a week-break for a home experience to try the newly learned behavior in the family setting.

Medical follow-up included initial examination and appropriate tests during regular clinical surveillance performed by the physician.

Subjects were weighed wearing underwear and barefoot on an electronic scale to the nearest $0.1 \mathrm{~kg}$ (weight scale Soehnle S20/2060). Height was measured to the nearest $0.5 \mathrm{~cm}$ by using a wall-mounted stadiometer. BMI was calculated as BW divided by height square $\left(\mathrm{kg} / \mathrm{m}^{2}\right)$. Body composition was assessed by bioelectrical impedance analysis (BIA) (2000-M Analyzer produced by DATA Input $\mathrm{GmbH}$, Frankfurt). All procedures are performed as previously described by Dittmar. ${ }^{17}$ According to Fernandes et al., BIA is an effective method to measure body composition in adolescents and presents a good correlation with visceral adiposity. ${ }^{18}$

The main elements of therapy consisted of reduced energy intake (1,500-1,800 kcal per day), dietetic education, physical exercises and psychotherapy. Diet was offered in five meals (three meals and two snacks) with high vitamin and fiber content, consisting of $52 \%$ carbohydrates, $30 \%$ fat, and $18 \%$ protein. All meals were prepared in the kitchen of the rehabilitation centre with the help of patients under the supervision of experienced cooks and nutritionists, who portioned each meal. The meals were calculated in accordance with the German Society of Nutrition (Deutsche Gesellschaft für Ernährung, DGE) and the guidelines of the optimierte mischkost (optimally mixed nutrition) based on initial daily food consumption and physical characteristics. ${ }^{19}$ Patients learned how to improve their nutritional behavior in theoretical and practical courses. Individual schedules of physical exercise were developed according to the initial medical and physical condition of the patients. The most relevant physical activities were swimming, hiking, biking, cross country skiing and lifting training (four sports units per week, each one lasting for at least 90 minutes). Psychotherapy consisted of a systemic and family-oriented approach with elements of behavior, analytic and relaxation methods. Parents were included in the therapy program in two-weekend seminars. During the rehabilitation period, patients attended their 
Table 1 - Anthropometric profile and body composition of severely obese adolescents before and after long-term multidisciplinary weight loss therapy

\begin{tabular}{|c|c|c|c|c|}
\hline & \multicolumn{2}{|c|}{ Boys } & \multicolumn{2}{|c|}{ Girls } \\
\hline & Baseline $(n=249)$ & After $(n=236)$ & Baseline $(n=479)$ & After $(n=459)$ \\
\hline Age (years) & $15.25 \pm 1.56$ & $15.87 \pm 1.58$ & $15.34 \pm 1.59$ & $16.01 \pm 1.60$ \\
\hline $\mathrm{BW}(\mathrm{kg})$ & $127.81 \pm 26.41$ & $99.96 \pm 19.57^{*}$ & $112.31 \pm 20.90^{+}$ & $90.57 \pm 15.41^{*+}$ \\
\hline Height $(\mathrm{m})$ & $1.75 \pm 0.09$ & $1.77 \pm 0.08^{*}$ & $1.67 \pm 0.07^{\dagger}$ & $1.68 \pm 0.07^{* \dagger}$ \\
\hline BMI $\left(\mathrm{kg} / \mathrm{m}^{2}\right)$ & $41.25 \pm 7.06$ & $31.84 \pm 5.37^{*}$ & $40.01 \pm 6.46^{+}$ & $32.26 \pm 5.27 *$ \\
\hline FFM (kg) & $73.68 \pm 12.74$ & $69.09 \pm 10.91^{*}$ & $57.46 \pm 7.56^{\dagger}$ & $53.48 \pm 6.29^{* \dagger}$ \\
\hline FFM (\%) & $58.33 \pm 6.41$ & $69.98 \pm 7.43^{*}$ & $51.86 \pm 4.96^{\dagger}$ & $60.04 \pm 5.65^{* \dagger}$ \\
\hline FM (kg) & $53.86 \pm 16.60$ & $31.07 \pm 12.25^{*}$ & $54.79 \pm 15.16$ & $36.98 \pm 10.99^{*+}$ \\
\hline FM (\%) & $41.48 \pm 6.24$ & $30.19 \pm 7.29^{*}$ & $48.14 \pm 5.00^{+}$ & $40.32 \pm 5.78^{*+}$ \\
\hline
\end{tabular}

$\mathrm{BMI}=$ body mass index BW = body weight; $F F M=$ fat free mass; $F M=$ fat mass.

* Different from baseline.

$\dagger$ Different between boys and girls (significance set at $p<0.05$ ).

individual school or took part in a professional training to test further professional goals. Multidisciplinary therapy was previously described by Siegfried et al. ${ }^{20}$

All data were analyzed by means of Statistics 6.0 for Windows with significance set at $p<0.05$ and expressed as mean \pm standard deviation (SD).

Comparisons before and after weight loss were made using paired $t$ tests, and comparisons between sexes used unpaired $t$ tests. Simple and multiple regression analyses were performed to examine the relationship between body composition and physical characteristic variables.

\section{Results}

A total of 249 boys and 479 girls were included. Mean age was not different for boys ( $15.25 \pm 1.56$ years) and girls (15.34 \pm 1.59 years). Of all patients who were admitted to treatment, only 13 boys (5.22\%) and 20 girls (4.17\%) did not complete therapy.

The physical characteristics of the 695 obese adolescents before and after weight loss program are show in Table 1.

BW, BMI and FFM ( $\%$ and $\mathrm{kg}$ ) were higher in boys than in girls, both before and after weight loss and only FM (\% and $\mathrm{kg}$ ) was higher in girls. BW, BMI, FM\% and FM kg steeply decreased in both sexes. During the treatment, males and females showed an increase in height. At baseline, FFM\% was higher in boys than in girls. After weight loss, the mean values reached a significant increase in boys and girls, respectively (Table 1 ).

In Table 2, no differences in time of therapy were observed. However, total BW loss $(27.84 \pm 12.49 \mathrm{~kg}$ in boys and $21.60 \pm 9.87 \mathrm{~kg}$ in girls); percentage BW loss (21.32 \pm 6.88 in boys and $18.79 \pm 6.36 \%$ in girls) and BMI decrease $\left(9.19 \pm 3.88 \mathrm{~kg} / \mathrm{m}^{2}\right.$ in boys and $7.72 \pm 3.98 \mathrm{~kg} / \mathrm{m}^{2}$ in girls) were significantly higher in boys than in girls.

The results of simple correlations are shown in Table 3. In both sexes, the decrease in total BW loss and total FM loss were best correlated with their values at baseline. However, all anthropometric and body composition parameters analyzed in this study exerted

Table 2 - Changes in BW and BMI in severely obese adolescents submitted to a long-term multidisciplinary weight loss therapy

\begin{tabular}{lcc}
\hline & Boys & Girls \\
\hline BW loss $(\mathrm{kg})$ & $27.84 \pm 12.49$ & $21.60 \pm 9.87^{*}$ \\
BW loss $(\%)$ & $21.32 \pm 6.88$ & $18.79 \pm 6.36^{*}$ \\
BMI loss $\left(\mathrm{kg} / \mathrm{m}^{2}\right)$ & $9.19 \pm 3.88$ & $7.72 \pm 3.98^{*}$ \\
Duration of treatment (weeks) & $26.21 \pm 7.4$ & $27.93 \pm 7.41$ \\
\hline
\end{tabular}

$\mathrm{BMI}=$ body mass index; $\mathrm{BW}=$ body weight.

${ }^{\star}$ Different between boys and girls (significance set at $p<0.05$ ). 
a significant effect on BW change. When multiple regression was performed, the strongest determinants of changes in BW in boys were initial BW and time of therapy $\left(r^{2}=0.79\right)$; in girls, the same variables plus initial BMI $\left(r^{2}=0.79\right)$ (Table 4). Regarding FM loss, the main determinants were FFM at baseline and time of therapy $\left(r^{2}=0.75\right)$ for boys and girls.

\section{Discussion}

In the past two decades, the world has experienced an increased prevalence of obesity, resulting in a global obesity epidemic.1,2 A key reason behind this epidemic is the lack of physical activity and food abundance. BW reduction as a result of exercise training and energy intake restriction is attributed to the change in energy balance;

Table 3 - Simple correlation coefficient between changes in BW and total fat mass and anthropometric measurements, body composition and duration of treatment in severely obese adolescents

\begin{tabular}{|c|c|c|c|c|}
\hline & \multicolumn{2}{|c|}{ Boys $(n=235)$} & \multicolumn{2}{|c|}{ Girls $(n=453)$} \\
\hline & $\mathbf{r}$ & $\mathbf{p}$ & $\mathbf{r}$ & $\mathbf{p}$ \\
\hline \multicolumn{5}{|l|}{ Change in BW } \\
\hline BMI at baseline & 0.65 & 0.000000 & 0.67 & 0.00 \\
\hline BW at baseline & 0.70 & 0.00 & 0.71 & 0.00 \\
\hline FFM at baseline & 0.57 & 0.000000 & 0.60 & 0.00 \\
\hline FM at baseline & 0.63 & 0.000000 & 0.70 & 0.00 \\
\hline Duration of treatment & 0.62 & 0.000000 & 0.54 & 0.00 \\
\hline \multicolumn{5}{|l|}{ Change in total fat mass } \\
\hline BMI at baseline & 0.62 & 0.000000 & 0.64 & 0.00 \\
\hline BW at baseline & 0.61 & 0.000000 & 0.66 & 0.00 \\
\hline FFM at baseline & 0.43 & 0.000000 & 0.46 & 0.000000 \\
\hline FM at baseline & 0.66 & 0.000000 & 0.70 & 0.00 \\
\hline Duration of treatment & 0.55 & 0.000000 & 0.51 & 0.0 \\
\hline
\end{tabular}

$\mathrm{BMI}=$ body mass index BW = body weight FFM = fat free mass; $F M=$ fat mass.

Table 4 - Multiple regression of the influence of anthropometric measurements, FFM and time of treatment on the changes in BW and total fat mass in severely obese adolescents

\begin{tabular}{|c|c|c|c|c|c|c|}
\hline & \multicolumn{3}{|c|}{ Boys $(n=235)$} & \multicolumn{3}{|c|}{ Girls $(n=453)$} \\
\hline & B (slope) & $\mathbf{p}$ & $\mathbf{r}^{2}$ & B (slope) & $\mathbf{p}$ & $\mathbf{r}^{2}$ \\
\hline Change in BW & & & 0.79 & & & 0.79 \\
\hline BW at baseline & 0.54 & 0.000000 & & 0.51 & 0.000000 & \\
\hline Duration of treatment & 0.42 & 0.000000 & & 0.35 & 0.000000 & \\
\hline BMI at baseline & & & & 0.09 & 0.13 & \\
\hline Change in total fat mass & & & 0.75 & & & 0.75 \\
\hline $\mathrm{FFM}(\mathrm{kg})$ at baseline & 0.54 & 0.000000 & & 0.59 & 0.000000 & \\
\hline Duration of treatment & 0.37 & 0.000000 & & 0.30 & 0.000000 & \\
\hline
\end{tabular}


in which EE is increased through physical exercise and energy intake is either maintained or reduced. ${ }^{15}$

The important finding of this study is that the described multidisciplinary weight loss program is able to decrease major obesity level, FM content and to improve FFM\% in severely obese adolescents.

The results of the present investigation showed that after long-term multidisciplinary inpatient therapy, including lifestyle education, moderate dietary restriction, regular physical training, psychological, clinical and educational support, induced considerable reduction in BW, FM and BMI, since these adolescents showed a decrease in BMI (9.19 \pm 3.88 and $7.72 \pm 3.99$ for boys and girls, respectively). Our data are consistent with others from previous studies. ${ }^{8,21}$ Dao et al., ${ }^{22}$ after 9 months of multidisciplinary intervention, showed higher mean reduction in BMI than observed in the present research. It is important to note that this difference could be partially explained by the duration of therapy.

Caloric restriction may induce negative side effects such as growth retardation. Therefore, a weight loss program in obese children and adolescents must ensure lasting growth and development. ${ }^{23}$ Despite negative energy balance, in the present study, no adverse effect was verified on height growth. The same result was reported by Lazzer et al., ${ }^{24}$ after a 9-month weight reduction period.

A study carried out in obese adults showed that a severe energy restriction associated or not with physical activity training resulted in significant FFM loss. ${ }^{15}$ Similarly, in adolescents, a severe energy restriction without physical training for 3 or 6 weeks or several months resulted in significant decreases in FFM. ${ }^{25,26}$ On the contrary, physical training associated or not with energy restriction favored FM loss and preserved FFM. ${ }^{11,27}$

According to previous research with obese adolescents, the FFM, which is the main determinant of EE, increased steeply in boys while showed the opposite trend in girls, both sexes submitted to an exercise protocol. 28 It is important to mention that, in the present investigation, after long-term multidisciplinary therapy, the obese adolescents (boys and girls) showed an increase in percentage of FFM; however, at baseline and after treatment, boys had higher FFM values than girls.

There is evidence that the resting metabolic rate (RMR) is largely dependent on FFM. ${ }^{10}$ RMR is the energy expended by active cells to maintain normal body functions at rest. In a recent review, Hansen et al. ${ }^{15}$ reported that RMR is a good predictor for long-term weight gain. During a 2-year follow-up, the risk of gaining $>7.5 \mathrm{~kg}$ of BW increased 4fold for those patients with a low adjusted 24-hour resting EE. Unfortunately, dietary restriction often leads to an additional decline in the basal fat oxidation. ${ }^{29}$ It reinforces the relevance of our results, since our patients presented increased percentage of FFM and strongly decreased total FM concomitantly. Therefore, we could speculate that this new body composition profile will be beneficial for longterm success in preventing weight regain.

Reduction in BW is correlated, in boys, with the initial BW only. In girls, it is correlated with the initial BW and FM at baseline. When we performed multiple regression analyses, the main determinant factors for $\mathrm{BW}$ reduction were initial BW and time of therapy $\left(r^{2}=0.79\right)$ in boys. The same factors were observed in girls plus BMI at baseline $\left(r^{2}=0.79\right)$. Total FM decrease is correlated with baseline values of FM, BMI and BW in both sexes. Multiple analyses revealed that time of therapy and initial FFM are the most important variables to determine these responses in boys and girls $\left(r^{2}=0.59\right)$ (Tables 3 and 4$)$. Other studies ${ }^{21,30}$ also reported steeper weight losses associated with a low calorie diet and presented a positive correlation between weight loss and duration of treatment.

\section{Conclusion}

Our results demonstrated that this kind of multidisciplinary therapy allows significant reduction in severe obesity, preserving growth and percentage of FFM. At similar obesity levels and age ranges, an additional favorable effect is found in boys. The results are also related to the 6-month duration of the inpatient program and initial values of BW, BMI, FFM and FM in obese adolescents.

\section{References}

1. World Health Organization. Obesity and overweight: World Health Organization global strategy on diet, physical activity and health. Geneva: WHO; 2008.

2. Instituto Brasileiro de Geografia e Estatística - IBGE. Pesquisa nacional de orçamento familiar, 2006. Rio de Janeiro, RJ: IBGE;2007.

3. Moreira SR, Ferreira AP, Lima RM, Arsa G, Campbell CS, Simões $\mathrm{HG}$, et al. Predicting insulin resistance in children: anthropometric and metabolic indicators. J Pediatr (Rio J). 2008;84:47-52.

4. Tock L, Prado WL, Caranti DA, Cristofalo DM, Lederman H, Fisberg $M$, et al. Nonalcoholic fatty liver disease decrease in obese adolescents after multidisciplinary therapy. Eur J Gastroenterol Hepatol. 2006;18:1241-5.

5. Strauss RS. Childhood obesity and self-esteem. Pediatrics. 2000;105:e15.

6. Livingstone B. Epidemiology of childhood obesity in Europe. Eur J Pediatr. 2000;159 Suppl1:S14-34.

7. Nowicka P, Hoglund P, Pietrobelli A, Lissau I, Flodmark CE. Family Weight School treatment: 1-year results in obese adolescents. Int J Pediatr Obes. 2008;3:141-7.

8. Taylor RW, Mcauley KA, Williams SM, Barbezat W, Nielsen G, Mann JI. Reducing weight gain in children through enhancing physical activity and nutrition: the APPLE project. Int J Pediatr Obes. 2006; 1:146-52.

9. Gately PJ, Cooke CB, Butterly RJ, Mackreth P, Carroll S. The effects of a children's summer camp programme on weight loss, with a 10 month follow-up. Int J Obes Relat Metab Disord. $2000 ; 24: 1445-52$. 
10. Stiegler $P$, Adam $C$. The role of diet and exercise for the maintenance of fat-free mass and resting metabolic rate during weight loss. Sports Med. 2006;36:239-62.

11. Sothern MS, Loftin M, Suskind RM, Udall JN Jr, Blecker U. The impact of significant weight loss on resting energy expenditure in obese youth. J Investig Med. 1999;47:222-6.

12. Lazzer S, Boirie Y, Montaurier C, Vernet J, Meyer M, Vermorel M. A weight reduction program preserves fat-free mass but not metabolic rate in obese adolescents. Obes Res. 2004;12:233-40.

13. Lissau I, Overpeck MD, Ruan WJ, Due P, Holstein BE, Hediger $\mathrm{ML}$, et al. Body mass index and overweight in adolescents in 13 European countries, Israel, and the United States. Arch Pediatr Adolesc Med. 2004;158:27-33.

14. Nemet D, Barkan S, Epstein Y, Friedland O, Kowen G, Eliakim A Short- and long-term beneficial effects of a combined dietarybehavior-physical activity intervention for the treatment of childhood obesity. Pediatrics. 2005;115:e443-9.

15. Hansen D, Dendale P, Berger J, van Loon LJ, Meeusen R. The effects of exercise training on fat-mass loss in obese patients during energy intake restriction. Sports Med. 2007;37:31-46.

16. Centers for Diseases Control. CDC reference charts: Developed by $y$ the National Center for Health Statistics in collaboration with the National Center for Chronic Disease Prevention and Health Promotion (2000). http://www.cdc.gov/growthcharts. Access: 10/01/2009.

17. Dittmar M. Reliability and variability of bioimpedance measures in normal adults: effects of age, gender and body mass. Am J Phys Anthropol. 2003;122:361-70.

18. Fernandes RA, Rosa CS, Buonani C, Oliveira AR, Freitas Júnior IF. The use of bioelectrical impedance to detect excess visceral and subcutaneous fat. J Pediatr (Rio J). 2007;83:529-34.

19. Deutsche Gesellschaft für Ernährung (DGE). Empfehlungen für die Ernährung von kinder und jugendlichen aid infodienst. Forschungsinstitut für Kinderernährung. Dortmund; 2002.

20. Siegfried W, Siegfried A, Rabenbauer M, Hebebrand J. Snoring and sleep apnea in obese adolescents: effect of long-term weight loss-rehabilitation. Sleep Breat. 1999;3:83-7.

21. Sothern MS. Exercise as a modality in the treatment of childhood obesity. Pediatr Clin North Am. 2001;48:995-1015.

22. Dao $\mathrm{HH}$, Frelut $\mathrm{ML}$, Oberlin $F$, Peres $G$, Bourgeois $P$, Navarro ]. Effects of a multidisciplinary weight loss intervention on body composition in obese adolescents. Int J Obes Relat Metab Disord. 2004;28:290-9.
23. Sothern MS, Udall JN Jr, Suskind RM, Vargas A, Blecker U. Weight loss and growth velocity in obese children after very low calorie diet, exercise, and behavior modification. Acta Paeditr. 2000;89:1036-43.

24. Lazzer S, Boirie Y, Poissonnier C, Petit I, Duché P, Taillardat $M$, et al. Longitudinal changes in activity patterns, physical capacities, energy expenditure, and body composition in severely obese adolescents during a multidisciplinary weight-reduction program. Int J Obes (Lond). 2005;29:37-46.

25. Zwiauer KF, Mueller T, Widhalm K. Resting metabolic rate in obese children before, during and after weight loss. Int J Obes Relat Metab Disord. 1992;16:11-6.

26. Tounian P, Frelut ML, Parlier G, Abounaufal C, Aymard N, Veinberg $\mathrm{F}$. Weight loss changes in energy metabolism in massively obese adolescents. Int J Obes Relat Metab Disord. 1999;23:830-7.

27. Gutin B, Barbeau P, Owens S, Lemmon CR, Bauman M, Allison J, et al. Effects of exercise intensity on cardiovascular fitness, tota body composition, and visceral adiposity of obese adolescents. Am J Clin Nutr. 2002;75:818-26.

28. Bitar A, Vernet J, Coudert J, Vermorel M. Longitudinal changes in body composition, physical capacities and energy expenditure in boys and girls during the onset puberty. Eur J Nutr. 2000;39:157-63.

29. van Aggel-Leijssen DP, Saris WH, Hul GB, van Baak MA. Shortterm effects of weight loss with or without low-intensity exercise training on fat metabolism in obese men. Am J Clin Nutr. $2001 ; 73: 523-31$

30. Valverde MA, Patin RV, Oliveira FL, Lopez FA, Vitolo MR. Outcomes of obese children and adolescents enrolled in a multidisciplinary health program. Int J Obes Relat Metab Disord. 1998;22:5139.30. Valverde $M A$, Patin RV, Oliveira FL, Lopez FA, Vitolo MR. Outcomes of obese children and adolescents enrolled in a multidisciplinary health program. Int J Obes Relat Metab Disord. $1998 ; 22: 513-9$.

\section{Correspondence:}

June Carnier

Rua Marselhesa, 535 - Vila Clementino

CEP: 04020-060 - São Paulo, SP - Brazil

Tel.: + 55 (11) 5572.0177

E-mail: junecarnier.pnut@epm.br 